\title{
Erratum
}

\section{Brother or Burden: An Experiment on Reducing Prejudice Toward Syrian Refugees in Turkey- ERRATUM}

\author{
EGOR LAZAREV AND KUNAAL SHARMA
}

doi:10.1017/psrm.2015.57 Published by Cambridge University Press, October 2015.

In the original version of this paper Egor Lazarev's secondary affiliation was not stated. It is the International Research Laboratory on Political Demography and Social Macro-Dynamics, RANEPA.

The publisher regrets this error.

\section{REFERENCE}

Egor, Lazarev and Kunaal Sharma. Brother or Burden: An Experiment on Reducing Prejudice Toward Syrian Refugees in Turkey. Political Science Research and Methods, available on CJO2015. doi:10.1017/ psrm.2015.57. 